\title{
Die Entdeckung und Entwicklung des Gletschergartens Luzern 1872-1972
}

\section{Luzern zur Zeit der Entdeckung des Gletschergartens}

Ein kurzer Rückblick auf die Veränderungen des Luzerner Stadtbildes im 19. Jahrhundert vermittelt Einblick in Zeitgeist und Zeitgeschehen und kann damit zum Verständnis beitragen, wie es zur Entdeckung und vor allem zur Erhaltung des Naturdenkmals Gletschergarten kam.

Nach 1830 sprengte die Stadt ihren mittelalterlichen Rahmen. Stadtmauern, Tore und Türme mussten als Verkehrshindernisse fallen. Die nahezu $400 \mathrm{~m}$ lange Hofbrücke aus dem 13. Jahrhundert, einst Wehrgang wie die Kapellbrücke, führte damals als bildergeschmückter Spazier- und Kirchweg dem seichten Seeufer entlang vom Zur-Gilgen-Haus am Kapellplatz zur Hofkirche. 1834 wurde ein erstes Teilstück, 1844 ein zweites und 1854 der restliche Teil der Hofbrücke vor der Hofkirche abgetragen und gleichzeitig das rechte Seeufer aufgefüllt. Am geradlinigen Uferdamm, Luzerns „nouveau quai”, entstanden monumentale Hotelbauten. Grosse Investitionen wurden getätigt, gewaltige finanzielle Risiken eingegangen; die Pioniere des Fremdenverkehrs blickten mit viel Optimismus in die Zukunft und erwarteten eine Zunahme des Tourismus.

Auch der Hauptverkehr, der sich bisher durch die Altstadt über die Reussbrücke als älteste und einzige befahrbare Brücke Luzerns gedrängt hatte, nahm 1870 mit dem Bau der Seebrücke seinen Weg über den neuen Quai.

1837 fuhr das erste Dampfschiff auf dem Vierwaldstättersee von Luzern nach Flüelen. Nach der Jahrhundertmitte erhielt Luzern die Eisenbahnanschlüsse an Olten und Zürich. 1871 erklomm die erste Zahnradbahn Europas die Rigi. Was Rang und Namen hatte, stieg in Luzern ab, bewunderte das Löwendenkmal und musste einen Sonnenaufgang auf Rigi-Kulm erlebt haben.

Auch die Umgebung des Löwendenkmals, noch 1860 eine ländliche Gegend vor den Toren der Stadt, nahe der Landstrasse nach Zürich, wurde zehn Jahre später rasch überbaut, beschleunigt durch den in diesem Quartier geplanten Bahnhofbau der OstWest-Bahn. Neben Wohnhäusern und Gewerbebetrieben entstanden auch schon die ersten „Sehenswürdigkeiten”, wie „Stauffers Museum der Alpentiere” und das „Meyer'sche Diorama”. Direkt beim Löwendenkmal befand sich damals schon seit über fünfzig Jahren ein „Naturalienkabinett” im Haus von Karl Pfyffer von Altishofen, des Initianten des Löwendenkmals.

Es konnte nur eine Frage der Zeit sein, bis auch das Randstück des „Steinbruchhofes” überbaut werden sollte, das unmittelbar nördlich an den Denkmalpark anschloss.

\section{Josef Wilhelm Amrein-Troller 1842-1881}

Im Frühjahr 1872 konnte der junge J. W. Amrein den Kaufvertrag über dieses unbeachtete Stück Wiesland abschliessen. Er beabsichtigte, in den dort anstehenden Sandsteinfels einen Weinkeller einzulassen.

Amrein entstammte einer Bauern- und Lehrerfamilie. 1860 trat er als Lehrling in das damals sehr bekannte Bankhaus Knörr in Luzern ein. Innerhalb kurzer Zeit stieg er dank seiner Tüchtigkeit zum Filialleiter für Speditions- und Wechselgeschäfte auf. Er musste von 1865 an anstelle seines erkrankten Vaters für die Familie sorgen. Daher begann der junge Kaufmann neben seinem Beruf einen Weinhandel. Nach seiner Heirat mit Marie Troller (1849-1931) im Jahre 1870 gedachte er, dieses Geschäft auszubauen und sich selbständig zu machen. Mit einem Darlehen seines Schwiegervaters erwarb Amrein das 9007 Quadratfuss (ca. $800 \mathrm{~m}^{2}$ ) messende Randstück des „Steinbruchhofes” zum Preis von 12159 Franken.

\section{Die Entdeckung des ersten Gletschertopfes am 2. November 1872}

Im Spätherbst wurde mit den Aushubarbeiten begonnen. Am 2. November stiessen die Arbeiter auf ein beckenförmiges Loch im Sandstein. Es ist das Verdienst von Dr. Franz Joseph Kaufmann (18251892), dieses eigenartige Loch, welches bereits durch Sprengungen stark beschädigt worden war, sofort als eiszeitliches Strudelloch erkannt und damit früh genug die ersten Schritte zur Erhaltung der ganzen Anlage eingeleitet zu haben. Kaufmann war zwar ausgebildeter Arzt, wirkte aber als Naturgeschichtslehrer an der Mittelschule in Luzern, der sogenannten „Höheren Lehranstalt”. Er darf als einer der bedeutendsten Schweizer Geologen der damaligen Zeit bezeichnet werden. Dieser erfolgreiche Wissenschaftler verfolgte bei seinen täglichen Spazier- 
gängen aufs Wesemlin aufmerksam die Bauarbeiten. Vielleicht hatte er schon vorher die Gletscherschliffe auf der Felsoberfläche beachtet. So ist auch verständlich, dass er den ersten bescheidenen Gletschertopf (heutiger Topf Nr. 5) sofort als solchen erkannte. Kaufmann bewog den Grundeigentümer J. W. Amrein, die Felssprengungen vorläufig einstellen und behutsam die weitere Oberfläche des Sandsteins freilegen zu lassen. Amrein stimmte zu, beeinflusst wohl auch durch seinen Bruder K. C. Amrein, der als Seminarlehrer in Hitzkirch tätig war und im selben Jahr durch seine Pfahlbauausgrabungen am Baldeggersee von sich reden gemacht hatte. Auf dessen Rat rief man auch bereits Anfang Dezember 1872 den jungen Dozenten Albert Heim (1849-1937) aus Zürich nach Luzern. Dies erwies sich als sehr weitsichtiger Schritt, denn auch als führender Schweizer Geologe und international anerkannter Gelehrter blieb Albert Heim bis zu seinem Tode ein tatkräftiger Förderer, Freund und wissenschaftlicher Berater des Gletschergartens. Bevor dieser berühmte Experte in Luzern einen ersten Augenschein nahm, waren bereits mehr als fünf Gletschertöpfe und ein grosser Teil der polierten und geschrammten Felsoberfläche abgedeckt worden.

\section{Der Entschluss zur Erhaltung des Naturdenkmals}

Bis dahin war alles normal verlaufen: Fachleute wurden zugezogen, die Fundstelle weiter abgedeckt,
Skizzen und Reliefs erstellt. Die Mitteilung über den sensationellen Fund ging durch die Schweizer Presse, und von seiten der Naturfreunde kam der schüchterne und idealistische Vorschlag, das Ganze zu erhalten, ohne dass man sich dabeigrosse Hoffnungen für die Realisierung dieser Idee machte. So ermunterte besonders auch Heim den Besitzer, die Gletschertöpfe nicht überbauen und damit zerstören zu lassen, wie das andernorts bei der Entdeckung von Naturdenkmälern wiederholt geschehen war.

Für J. W. Amrein gab es hierzu aber einiges zu bedenken und abzuwägen. Von aussen durfte er keine finanziellen Unterstützungen erwarten. Seine eigenen Mittel waren bescheiden, hatte er sich doch schon mit dem Ankauf des Grundstückes in Schulden gestürzt. Zudem war ihm auch klar, dass „Amreins Löcher", wie die spottlustigen Luzerner seine Sehenswürdigkeit nannten, als Anziehungspunkt allein nicht genügten, um ihm und seiner Familie die Existenz zu sichern. Trotzdem stellte Amrein seine geschäftlichen Interessen in den Hintergrund, und Heim konnte später berichten: „Die Initiative zu wagen und auszuführen ist ganz das Verdienst von Herrn Amrein.” Bereits am 10. Dezember 1872, also gut einen Monat nach der Entdeckung, und unmittelbar nach dem Besuch Heims, kaufte Amrein das Tobel des Wesemlinbaches (5290 Quadratfuss ca. $470 \mathrm{~m}^{2}$ ) dazu. Sein Entschluss war also bereits gefasst. Um den grössten Gletschertopf mit über $9 \mathrm{~m}$ Tiefe und $8 \mathrm{~m}$ Durchmesser ausgraben zu können, der zum grössten Teil in das Nachbargrundstück hin-

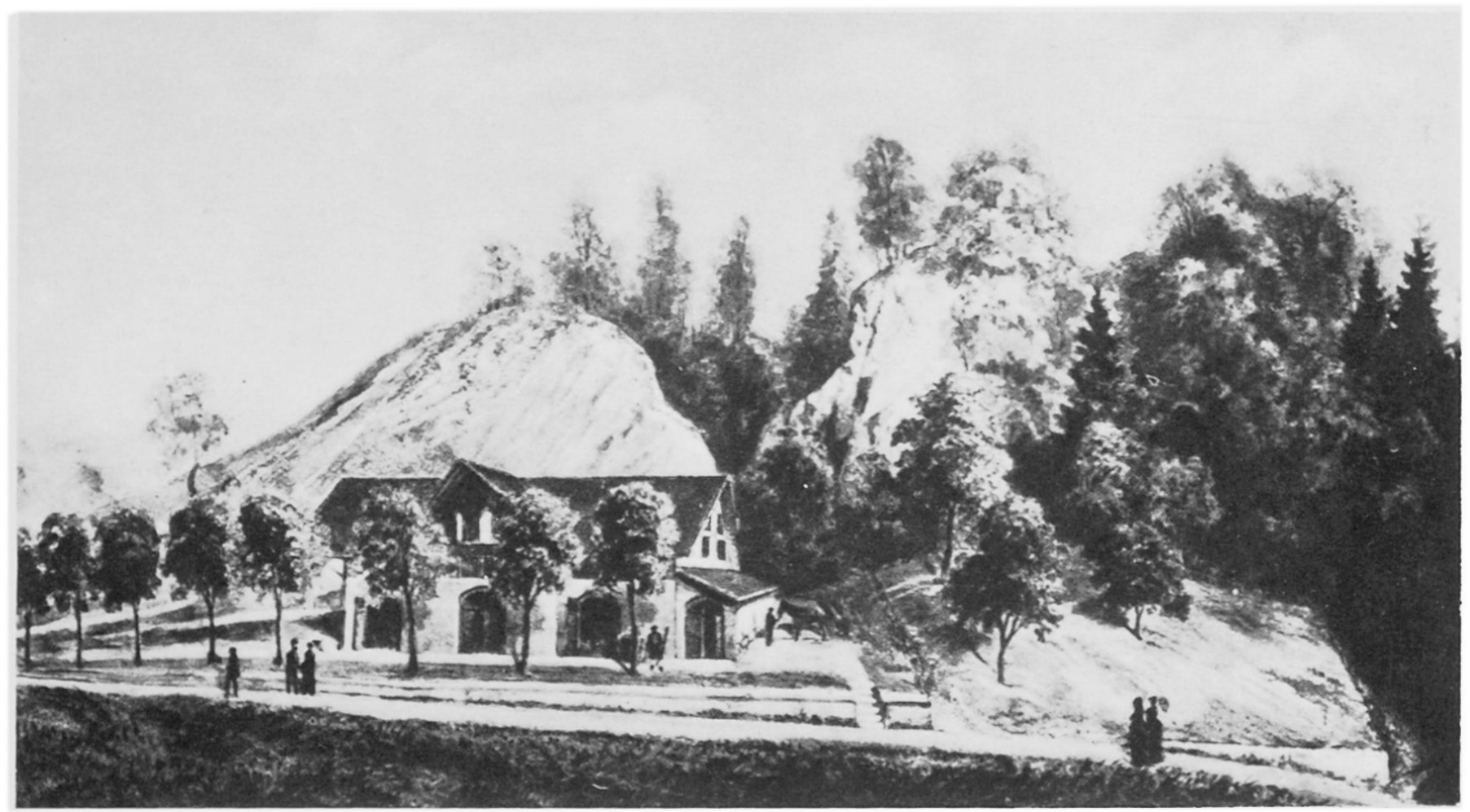

Ansicht der Umgebung des Gletschergartens Luzern vor der Entdeckung und den Ausgrabungen. Oktober 1872 
einragte, war es nötig, auch noch dieses dazuzukaufen. Mit diesem dritten Grundstück musste er eine fast neue Scheune, einen Pferdestall und 700 Zentner Heu und Emd übernehmen, was ihn zusätzliche Fr. 50 000.- kostete.

Die Ausgrabungen dauerten mit verschiedenen Unterbrüchen bis in den Winter 1875/76. Was aber hier alles zum Vorschein kam, verdient den Namen Naturdenkmal mit Recht.

\section{Vom palmenbestandenen miozänen Meeresstrand zur Gletscherwelt der Eiszeit}

Im Rahmen dieses Beitrages soll keine weitere wissenschaftliche Beschreibung des Gletschergartens vorgelegt werden. Einige methodische Bemerkungen drängen sich aber bei der Betrachtung des Naturdenkmals auf. Im Gletschergarten lassen sich auf einfache und allgemeinverständliche Art die Arbeits- und Denkweise der Geologie und Geomorphologie vermitteln. Einige Begriffe der Paläogeographie und Paläoklimatologie lassen sich direkt am „Aufschluss" entwickeln.

Der „Luzerner Sandstein”. Der miozäne „Luzerner Sandstein" wird ins Burdigalien eingestuft und ist Bestandteil der Oberen Meeresmolasse. Diese für den Laien unverständliche Aussage kann hier eindrücklich veranschaulicht werden. Wellenfurchen auf den Schichtflächen beweisen, dass der Sandstein ursprünglich als loser Sand in einem untiefen Gewässer abgelagert wurde. Die Körner des Sandsteins - vor allem die gelegentlich auftretenden Gerölle lassen den Schluss zu, dass in diesem Sedimentgestein ein Abtragungsprodukt der damaligen Alpen vorliegen muss. Der im Gletschergarten und in seiner unmittelbaren Umgebung sichtbare Fossilinhalt des „Luzerner Sandsteines” - marine Muscheln, Seesterne, Haifischzähne, Palmblätter u. a. - zeigt recht eindrücklich, dass vor ungefähr zwanzig Millionen Jahren die Umgebung von Luzern den Küstensaum eines Meeres gebildet hatte. Subtropische Galeriewälder zogen sich den Ufern von Meer und Flussläufen entlang. Eine Rekonstruktion dieser miozänen Landschaft in Form eines grossen Wandgemäldes konnte 1968 durch den Luzerner Kunstmaler Ernst Maass vollendet werden. Die Sandsteinschichten sind ursprünglich annähernd horizontal abgelagert worden; das zeigen schon die Wellenfurchen. Heute fallen die Schichten im Gletschergarten in einem Winkel von $45^{\circ}$ nach Norden ein. Als in der letzten bedeutenden Phase der Alpenfaltung die Schiefstellung der Schichten erfolgte, war der Sandstein bereits durch Infiltration von Kalklösungen weitgehend verhärtet. Dieser Vorgang hatte sich während den langen Ruhephasen vollzogen, die jeweils nur relativ kurz-

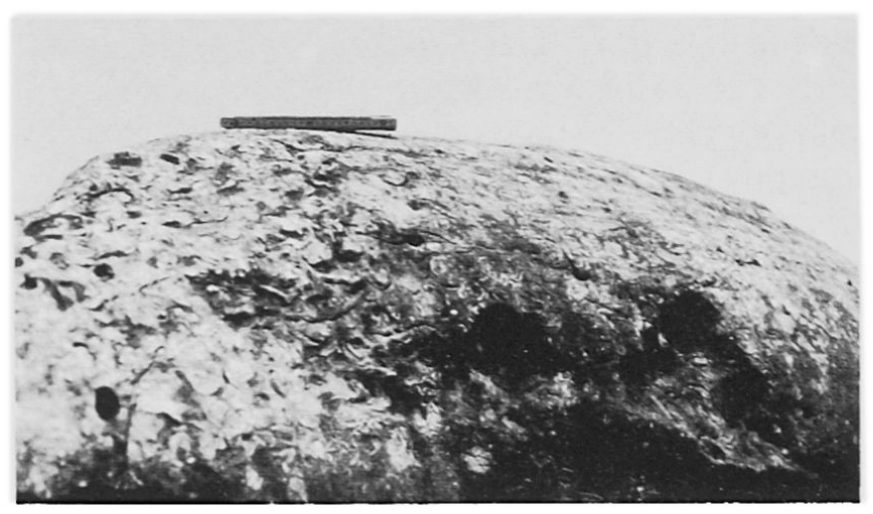

Luzerner Sandstein mit „Tapes helvetica”. Auf der rundgeschliffenen Felsoberfläche erkennt man parallele Gletscherschrammen

fristig durch die Bewegungsphasen der alpinen Orogenese unterbrochen worden sind.

Der Luzerner Sandstein wurde schon seit Jahrhunderten als Baustein verwendet. Die ehemaligen Steinbrüche am Fuss des Wesemlinhügels finden sich bereits auf der Stadtansicht von Martinus Martini (1597) verzeichnet. Aus dem schönen grauen Stein wurden viele Brunnenfiguren erstellt, Hausfassaden mit ihm verziert und auch die Hofkirche nach dem Brand von 1633 neu aufgebaut. Aus einer Steinbruchwand ist auch Thorvaldsens berühmter Luzerner Löwe 1820/21 gemeisselt. Der „Luzerner Sandstein" lässt sich zwar leicht bearbeiten, weist aber leider eine äusserst geringe Resistenz auf. Dies bekamen schon manche Hausfassade, mancher Brunnenschmuck, das Löwendenkmal und ebenfalls der Gletschergarten zu spüren. Die Zunahme der aggressiven Bestandteile in der Luft wie Salzsäure und Schwefelsäure beschleunigen seit der Jahrhundertwende noch die Verwitterung des ohnehin schon „weichen” Sandsteins.

Die Spuren der eiszeitlichen Vergletscherung. Obwohl die tertiären Fossilien im „Luzerner Sandstein” schon von Anfang an bekannt waren, werden sie eigentlich erst seit der Errichtung des Neubaues (1970) mit dem Motto „Wo Steine reden” vom Grossteil der Besucher gebührend beachtet. Zusammen mit den schon von Beginn an berühmten Spuren der Eiszeit zeigt das Naturdenkmal einen interessanten Ausschnitt aus der jüngeren Erdgeschichte.

Das ca. $20 \times 34$ m messende abgedeckte Felsareal bildet eine kleine Rundhöckerlandschaft. Die Leeseiten der Rundhöcker laufen parallel zu den Schichtflächen. Die geschliffene Sandsteinoberfläche wird von parallelen von Süden nach Norden verlaufenden Gletscherschrammen durchzogen. Diese Schrammen waren zur Zeit der Ausgrabung noch recht auffällig in den Fels geprägt. Durch die Verwitterung der Felsoberfläche im Verlauf der ver- 
gangenen hundert Jahre sind sie leider unscheinbar geworden. Die Schliffspuren verlaufen bis unmittelbar an die Kanten der Gletschertöpfe, was für deren Interpretation von Bedeutung ist.

Die Ausgrabungen der Jahre 1872-1875 förderten eine grosse Anzahl erratischer Blöcke zutage. Neben eindeutig lokalisierbaren Leitgesteinen (z. B. Altdorfer Sandstein) fanden sich auch andere Findlinge aus den Helvetischen Decken und der Subalpinen Molasse aus dem Einzugsgebiet des Reussgletschers. Einige Blöcke enthalten schöne Versteinerungen wie z. B. eine Kalkplatte mit Alectryonia (Austern) aus der Untern Kreide, ferner tertiäre Nummulitenkalke und -sandsteine. Die Kalkfindlinge weisen z. T. tiefe Karren auf (Schrattenkalk). Das auffälligste Merkmal der Vergletscherung im Luzerner Gletschergarten sind die berühmten und eindrücklichen Gletschertöpfe. Der Entstehung dieser Formen ist ein wissenschaftsgeschichtlicher Rückblick am Schluss dieses Beitrages gewidmet.

\section{Eröffnung des Gletschergartens und Gründung des Museums}

Gleichzeitig mit dem Entschluss, das Naturdenkmal zu erhalten, sah sich J. W. Amrein-Troller vor die Aufgabe gestellt, dieses auch attraktiv zu gestalten.
Wie gesagt, genügten die aufgefundenen geologischen Phänomene allein nicht, um eine die Existenz des Betriebes sichernde Anzahl von Besuchern anzuziehen. Zwei glückliche Umstände kamen J. W. Amrein schon vor der Eröffnung zu Hilfe. Sein jüngerer Bruder K. C. Amrein übergab ihm eine Sammlung von Fundgegenständen seiner 1872 durchgeführten Ausgrabung der Pfahlbauten vom Baldeggersee (,Seematte” Richensee). Das älteste erhaltene Relief der Schweiz von Franz Ludwig Pfyffer von Wyher (1716-1802), das in seiner Art einmalig ist und die Urschweiz darstellt, war schon seit dem ausgehenden 18. Jahrhundert eine in ganz Europa bekannte Sehenswürdigkeit. Bis 1865 blieb das Relief im Besitz der Familie Pfyffer, dann wurde es der Korporationsgemeinde Luzern zuhanden der Bürgerbibliothek geschenkt. 1872 erwog man aus Platzgründen, das Relief in eine Baracke im Lindengarten oder auf die Laube des Wasserturms zu versetzen. Amreins Idee, in seinem im Aufbau begriffenen Freilichtmuseum ein eigenes Gebäude für das Relief zu erstellen, war wirklich im richtigen Augenblick gekommen. Bereits am 28. Januar 1873 konnte er den Vertrag mit der Korporationsverwaltung abschliessen, der es ihm ermöglichte, das Pfyfferrelief im Gletschergarten auszustellen. Dieser Vertrag ist heute noch in Kraft. Das Relief steht jetzt in einem eigens dafür erstellten Anbau, der mit einer

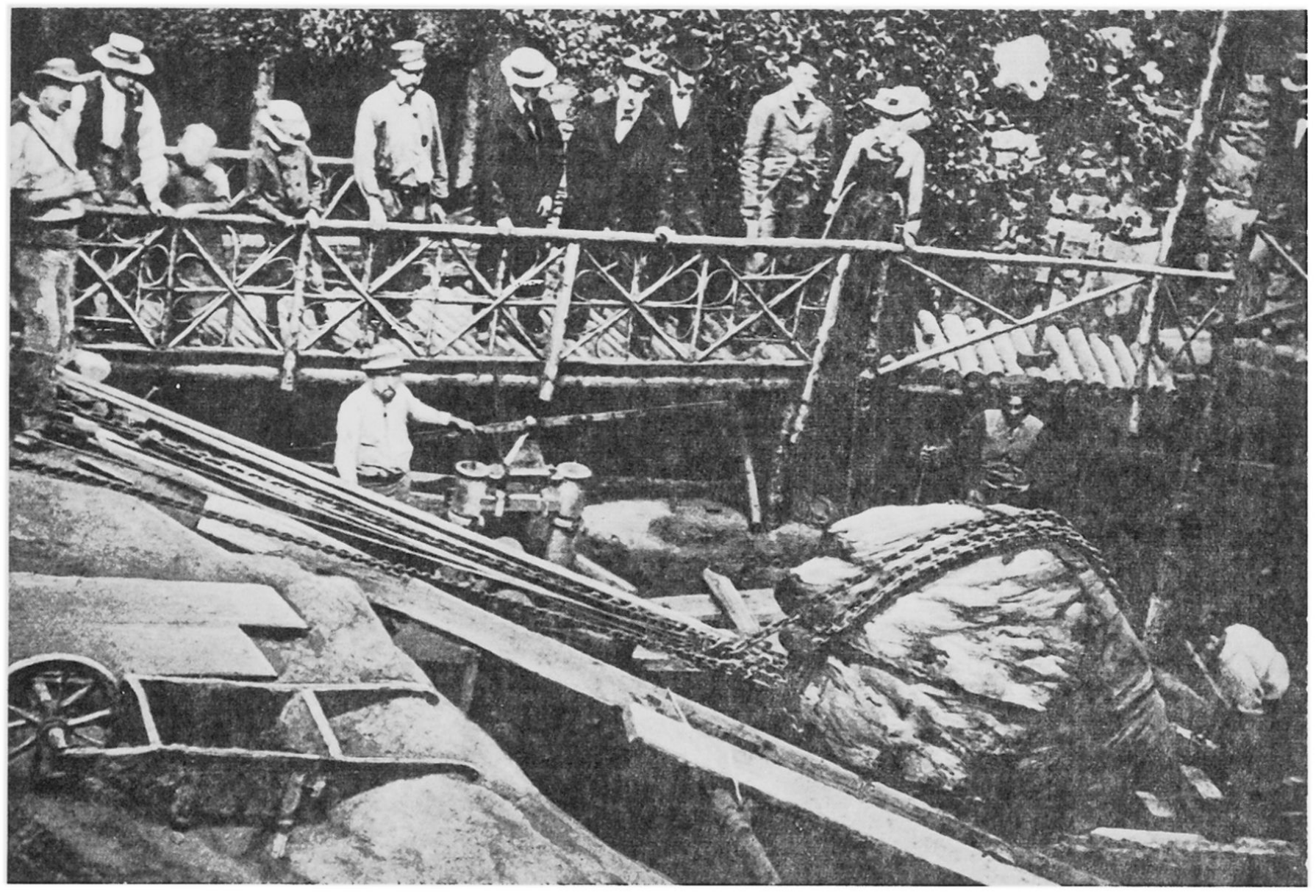

Ausgrabungsarbeiten am grossen Gletschertopf um 1875 


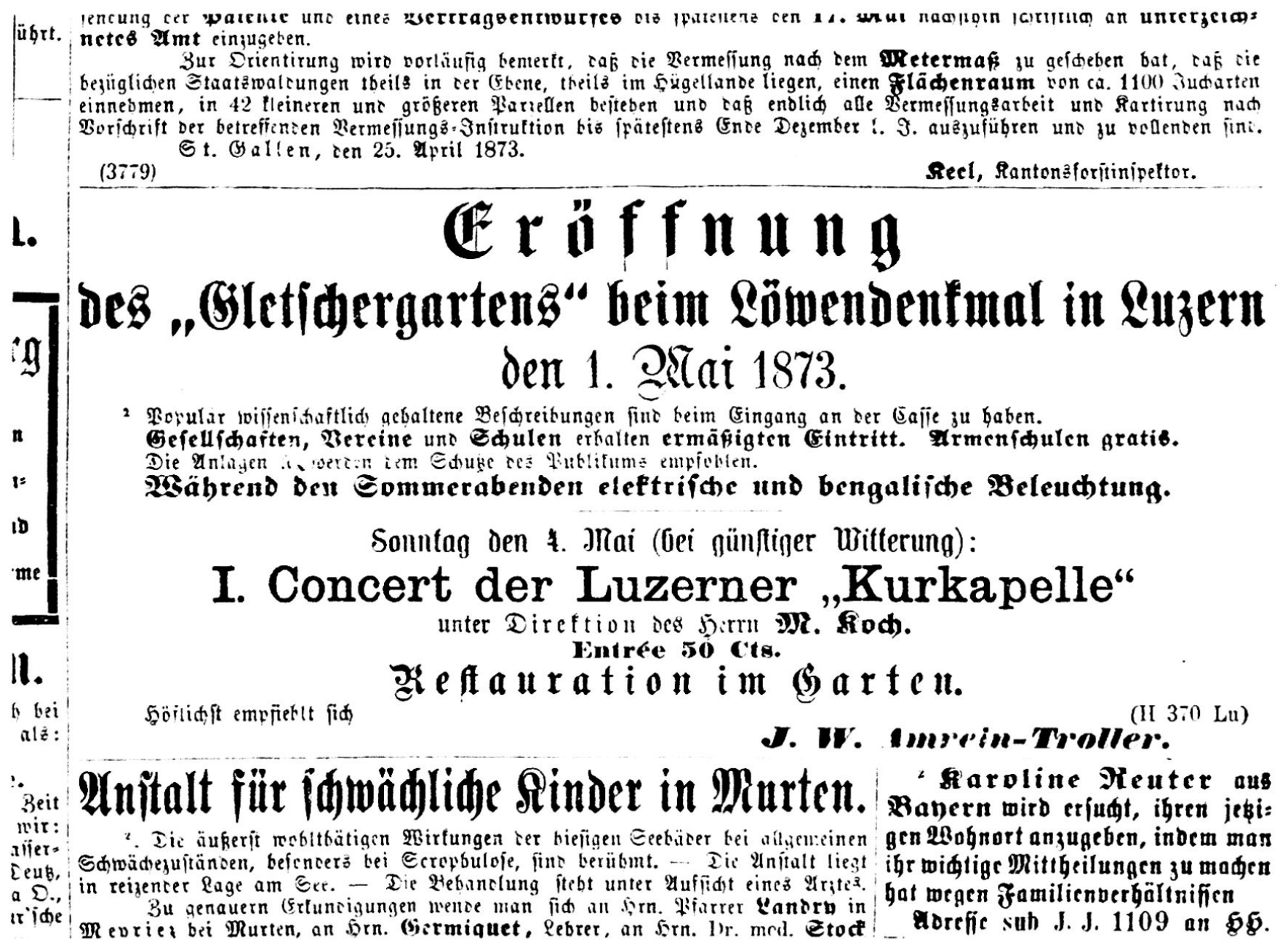

Inserat, das die Eröffnung des Gletschergartens am 1. Mai 1873 anzeigte

Galerie versehen ist, die es ermöglicht, dieses bewunderungswürdige Werk auch aus der Vogelschau zu besichtigen. Eine Arbeit von Dr. Th. Ottiger, Luzern, über die Geschichte dieses Reliefs erscheint gleichzeitig mit der Geschichte des Gletschergartens in diesem Heft.

Durch die genannten zwei Ausstellungsobjekte war der Grundstock zum späteren Museum bereits vor der Eröffnung des Gletschergartens gelegt.

Amreins nächste Aufgabe, dem Naturdenkmal einen passenden Namen zu geben, war auch bald gelöst. Vorerst wollte er in Anlehnung an das 1864 erschienene Werk „Die Urwelt der Schweiz” von Oswald Heer die Parkanlagen "Garten der Urwelt" nennen. Er wählte aber die einfachere Bezeichnung "Gletschergarten”. Dieser Begriff ist in die wissenschaftliche Literatur eingegangen und wird auch für andere Fundorte von Gletschertöpfen verwendet. Trotzdem verursacht dieser Name bis heute noch Missverständnisse, erwarten doch immer noch einzelne Besucher, hier ein Stück „ewigen Eises” zu sehen!

Selbstverständlich verbreitete sich die Nachricht von den Entdeckungen im Gletschergarten auch in der damaligen Presse. Vor allem in auswärtigen Zeit- schriften sahen sich die Journalisten anscheinend oft genötigt, darauf hinzuweisen, dass dies hier kein „Schwindel der Neuzeit”, keine „gemeinste Prellerei”, kein „niederträchtigster Humbug” sei, und „dass das alleräusserste Misstrauen, das dem nur halbwegs gewiegten Touristen zur zweiten Natur wird", hier nicht angebracht sei - ein wenig schmeichelhaftes Zeugnis für den damaligen Fremdenverkehr in der Schweiz. Im April 1873 erschien bereits der erste Pressebericht über den Gletschergarten in den USA.

Am 1. Mai 1873 war es soweit: der Gletschergarten Luzern wurde eröffnet. Mit welchem Enthusiasmus J. W. Amrein als Gründer seine Institution vorstellte, zeigt schon das abgebildete Eröffnungsinserat, welches in verschiedenen Zeitungen erschienen war.

Neben den Pfahlbaufunden vom Baldeggersee und dem Pfyfferrelief erhielt der Gletschergarten im ersten Jahr noch weitere Ausstellungsobjekte. Das Relief der Schlacht zwischen den Russen und Franzosen im Muotatal (1799) fand nach seiner langen Reise in verschiedene Hauptstädte Europas seinen endgültigen Platz ebenfalls im Gletschergarten. Im Park entstanden ein „Schweizerhäuschen”, eine 
„Einsiedelei” und ein „Wildkirchli”. Eine als „Löwenblick" bezeichnete Galerie gestattete die „schönste Aussicht auf das Löwendenkmal".

Einnahmen in der Höhe von Fr. 13785.25 konnte Amrein aus Eintrittsgeldern und Wirtschaftsbetrieb am Ende des Eröffnungsjahres buchen. Damit wurde er kaum „über Nacht zum reichen Mann”, wie verschiedene Pressestimmen damals behaupteten. Nachdem 1874 ein Wohnhaus mit sechs „herrschaftlichen" Wohnungen und einem Restaurant aufgebaut worden war, wurde 1875 über der Felswand auf der Nordseite des Gletschergartens ein hölzerner Aussichtsturm aufgestellt. Von dieser Warte aus genoss man einen prächtigen Rundblick über Stadt, Berge und See.

Die Sensation des Jahres 1875 war aber die Freilegung des grössten Gletschertopfes, welche erst durch den bereits erwähnten dritten Landkauf möglich geworden war. Bis sechs Tonnen schwere Findlinge wurden mittels Ketten und Winden aus dem tiefen Loch gezogen. Gut $9 \mathrm{~m}$ Tiefe und $8 \mathrm{~m}$ im Durchmesser misst dieser Riesentopf, der durch seine elegant verschlungenen Erosionsrinnen einige Anhaltspunkte liefert, um seine Entstehungsart zu ergründen. Mit der Freilegung des damals grössten je entdeckten Gletschertopfes erhielt der Gletschergarten den zu dieser Zeit sehr begehrten Stern im „Baedeker”.

\section{Die Entwicklung bis zum Tode J. W. Amreins im Jahre 1881}

Dem Gründer des Gletschergartens gelang es auch nach den ersten aufsehenerregenden Ausgrabungen, seine Sehenswürdigkeiten ständig mit Neuigkeiten zu bereichern. Auf verschiedenste Art konnte er durch geschickte Werbung den Gletschergarten in der ganzen Welt bekanntmachen, und dies in wissenschaftlichen wie auch touristischen Kreisen. So wandten neben Albert Heim verschiedene andere berühmte Gelehrte ihr Interesse dem Gletschergarten zu und beschrieben ihn zum Teil in ihren Publikationen. E. Désor (Neuenburg), Oswald Heer (Zürich), Bernhard Studer (Bern), F. A. Forel (Lausanne), Adolf Lasard (Berlin), John Tyndall (London), T. H. Huxley (London), Charles Lyell (London), und andere bekannte Namen aus der Besucherund Korrespondenzliste des Gletschergartens zeugen vom Aufsehen, welches diese Entdeckung gemacht hatte. Amrein versandte Broschüren, Photos und Reliefs an die Sektionen der Naturforschenden Gesellschaft der Schweiz. Inserate erschienen in allen wichtigsten Reisehandbüchern. Für die Bevölkerung Luzerns wurden damals Gratistage eingeführt. Neben einer Serenade für Singstimme und Klavier „Erinnerungen an den Gletschergarten” (Text: L. Schmid, Melodie: Gustav von der Bank) kompo- nierte Kéler Béla 1877 auf Amreins Auftrag den „Gletschergarten-Walzer” für Orchester.

1880 liess Amrein eine „dynamo-elektrische Maschine" installieren, welche die Wasserkraft des Hochspringbrunnens im Löwendenkmalweiher ausnützte und ihm erlaubte, den Gletschergarten samt dem Löwendenkmal elektrisch zu beleuchten. Diese erste elektrische Beleuchtungsanlage in Luzern kann sicher als eine weitere Pioniertat bezeichnet werden.

Andererseits setzte sich Amrein auch für die Verschönerung der Stadt ein. Er unternahm immer wieder Vorstösse für eine bessere Pflege der Anlagen um das Löwendenkmal und liess selbst die versumpfte Strasse im Weyquartier verbessern. 1880 lud er eine Reihe einflussreicher Herren zur Gründung des „Verschönerungsvereins der Stadt Luzern” ein. Kurz vor seinem Tod übergab er den Schulen seiner Vaterstadt eine umfangreiche Mineraliensammlung.

Während der Besuch des Gletschergartens zu einem „Muss” für alle die Zentralschweiz bereisenden Touristen aus nah und fern wurde, während der idyllische Gletschergartenwalzer die Runde durch die Konzertsäle Europas machte und während die Presse und die einheimische Bevölkerung den „reichen” Amrein beneideten, hatte dieser mit grossen finanziellen Schwierigkeiten zu kämpfen. Die durch den Deutsch-Französischen Krieg (1870/71) bedingte Wirtschaftskrise machte es immer schwieriger, für die Erhaltung eines immateriellen Wertes, wie es das Naturdenkmal darstellte, Kredite zu bekommen. Das früher führende Bankunternehmen Knörr, das Amrein unter anderen ein Darlehen gewährt hatte, brach 1877 zusammen. Viele Hotels mussten, kaum eröffnet, wieder schliessen und die Bautätigkeit ruhte. Nach vergeblichen Versuchen, in London, wo der Gletschergarten bereits bekannt war, verständnisvolle Geldgeber zu finden, erhielt Amrein 1878 endlich ein grösseres Darlehen aus Basel. Die grössten Sorgen waren im Moment behoben. Die steigenden Besucherfrequenzen erlaubten der jungen Familie, optimistisch an eine Amortisierung der eingesetzten Mittel zu denken. Doch die materielle Festigung seines begeistert begonnenen Werkes sollte der Gründer nicht mehr erleben. J.W. AmreinTroller, der als realistisch denkender Geschäftsmann sich nicht gescheut hatte, so viel für die Erhaltung eines Naturdenkmals aufs Spiel zu setzen, starb am 20. Juli 1881 im Alter von nur 39 Jahren.

\section{Marie Amrein-Troller (1849-1931) übernimmt die Leitung des Gletschergartens}

Durch den allzu frühen Tod des Gründers verlor der Gletschergarten seinen aktiven Betriebsleiter, und das noch im Aufbau begriffene Unternehmen stürz- 


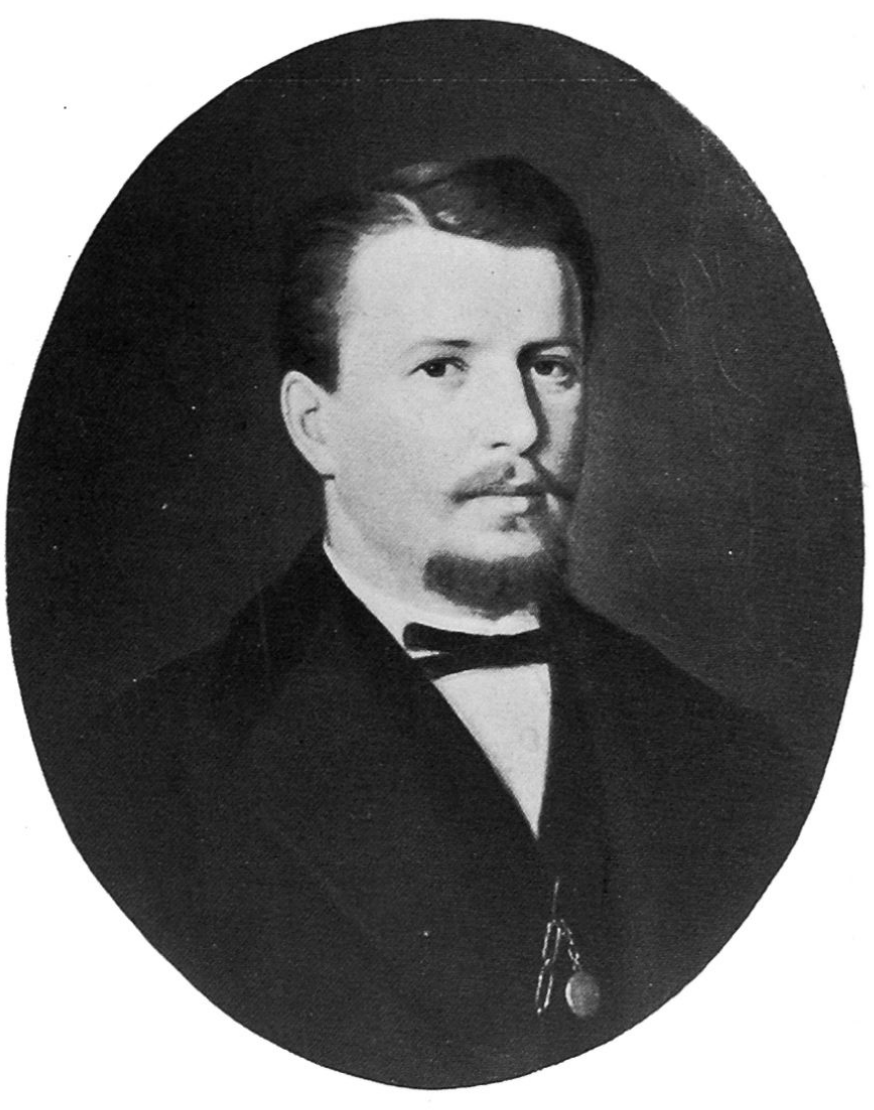

Josef Wilhelm Amrein-Troller (1842-1881). Gründer des Gletschergartens Luzern

te in eine tiefe Krise. Die Liegenschaft war schwer belastet, und ein grosser Schuldenberg musste abgebaut werden. Die 32 jährige Marie Amrein-Troller hatte zudem noch vier Kinder von sechs bis zehn Jahren zu betreuen. Niemand traute der jungen Witwe zu, dass sie die grosse Aufgabe meistere, die ihrer harrte, und auf die sie nicht vorbereitet war. Die Geldgeber wurden ängstlich und kündigten die Darlehen; selbst die nächsten Verwandten drängten zum Konkurs. Durch einen Vertrag blieb dann der Gletschergarten wohl zu einem Drittel im Besitz von Frau Amrein, aber die Vertragsbedingungen lauteten so ungünstig, dass sie eine Weiterentwicklung des Betriebes verhinderten. Für die Witwe begann eine Zeit äusserster Sparsamkeit und Angst vor ungenügender Rendite. Sie haftete persönlich voll für alle weiteren Fremdkapitalien, obwohl sie nur zu einem Drittel am Gewinn beteiligt war. Sie sorgte für ihre Familie, erzog die Kinder, leitete den Gletschergarten, sass oft selbst an der Kasse und überwachte den Restaurationsbetrieb. Der Gletschergarten stagnierte bis ins Jahr 1895, als endlich der ungünstige Vertrag mit Hilfe des Schwiegersohnes L. Akesson-Amrein auf rechtlichem Wege aufgelöst werden konnte.

\section{5-1914: Der grosse Aufschwung und Ausbau des Gletschergartens}

1882 wurde die Gotthardbahn eröffnet, und einige Jahre später erhielt Luzern seinen Anschluss an diese wichtige Transitlinie. In den frühen neunziger Jahren begann für Luzern die eigentliche Blütezeit des Fremdenverkehrs. Die jährlichen Besucherzahlen im Gletschergarten, die bis 1895 fast ausnahmslos unter 40000 lagen, konnten innerhalb von zehn Jahren auf über 90000 gesteigert werden. Der vom Gründer des Gletschergartens vorgezeigte Weg zur weitern Ausgestaltung des Gletschergartens konnte nun zum Teil verwirklicht werden. Als grosse Stütze von Marie Amrein-Troller beteiligte sich seit ihrem 18. Lebensjahr die Tochter Mathilde (Blattner-)Amrein (1873-1962) an der Leitung des Betriebes. Unter der Führung dieser beiden Frauen wurde das grosse Wohnhaus nun etappenweise zu einem $\mathrm{Mu}-$ seum umgebaut. Durch ihre Freude an alten Möbeln, Gerätschaften und Graphiken entwickelte sich das Haus zu einem der ersten „Heimatmuseen”. Im ehemaligen Wohnhaus und seinen neu erstellten Anbauten wurde eine Anzahl Reliefs bekannter Reliefkünstler wie Heim, Imfeld, Becker und Meili ausgestellt. Abteilungen mit Mineralien-, Fossilien- und Gesteinssammlungen wurden angefügt. Eine „Lesehalle”, die Räume „Flora Alpina” und „Alt Luzern” vervollständigten das vielseitige Bild des Museums. Der einzige Sohn der Familie, Wilhelm Amrein, fügte, noch bevor er die Leitung des Gletschergartens übernahm, Ausstellungen über Natur- und Heimatschutz, über den kurz vorher (1910) gegründeten Nationalpark und über die Entwicklung des Menschen bei. Ihm war bereits bewusst, dass diese Vielseitigkeit auch die Gefahr in sich barg, ein unübersichtliches Durcheinander zu werden.

Schon 1909 wurden in Form von Kunstausstellungen die ersten Wechselausstellungen veranstaltet.

Die Entstehung der Gletschertöpfe wurde seit der Eröffnung des Gletschergartens in einer kleinen

„Luzern zur Eiszeit”: Wandgemälde (2 x 6 m) von Ernst Hodel (1927) im Museum des Gletschergartens. Wissenschaftliche Berater: Prof. Dr. Albert Heim, Zürich, und Dr. h. c. Wilhelm Amrein-Küpfer.

(Photoglob-Wehrli AG, Zürich)

„Luzern zur Miozänzeit”: Wandgemälde von Ernst Maass (1968) im Gletschergartenmuseum. Wissenschaftliche Berater: Prof. Dr. E. Kuhn-Schnyder, Prof. Dr. R. Hantke, Zürich, und Dr. F. Roesli, Luzern. (Photoglob-Wehrli AG, Zürich) 


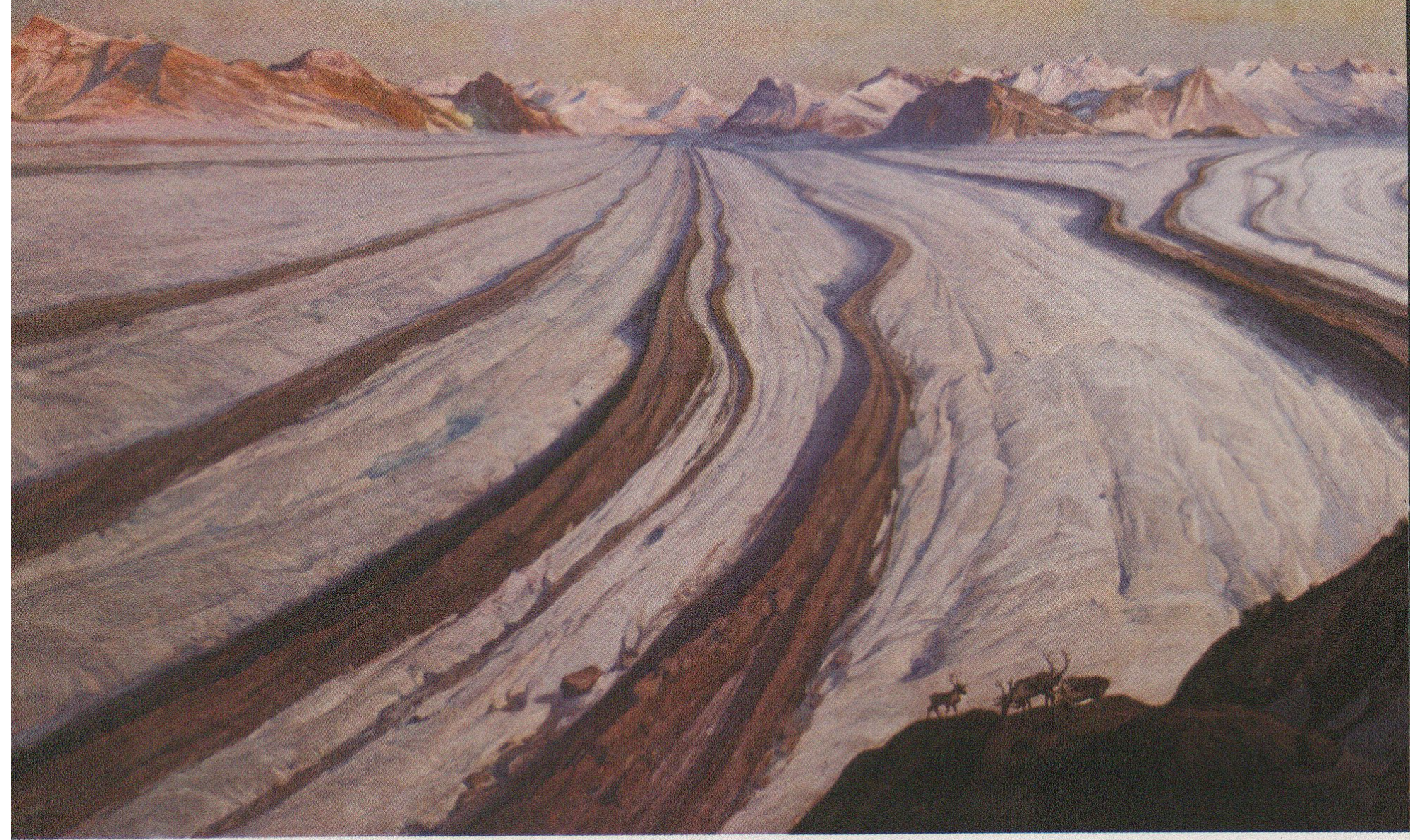

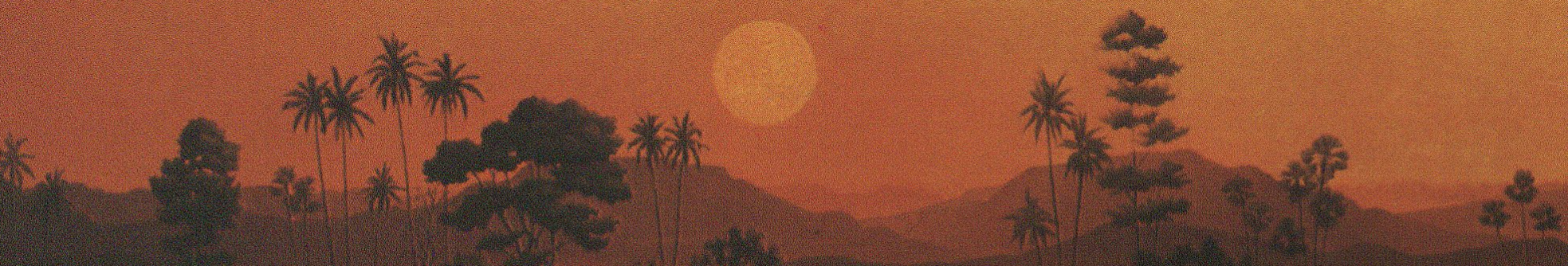

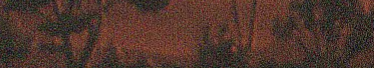

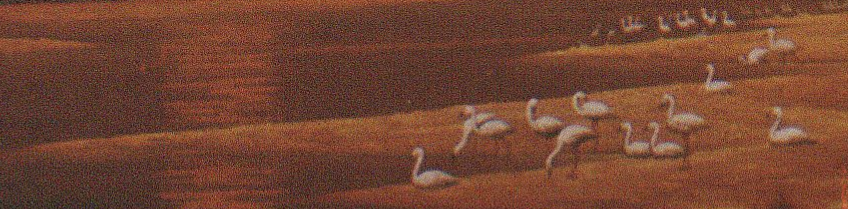




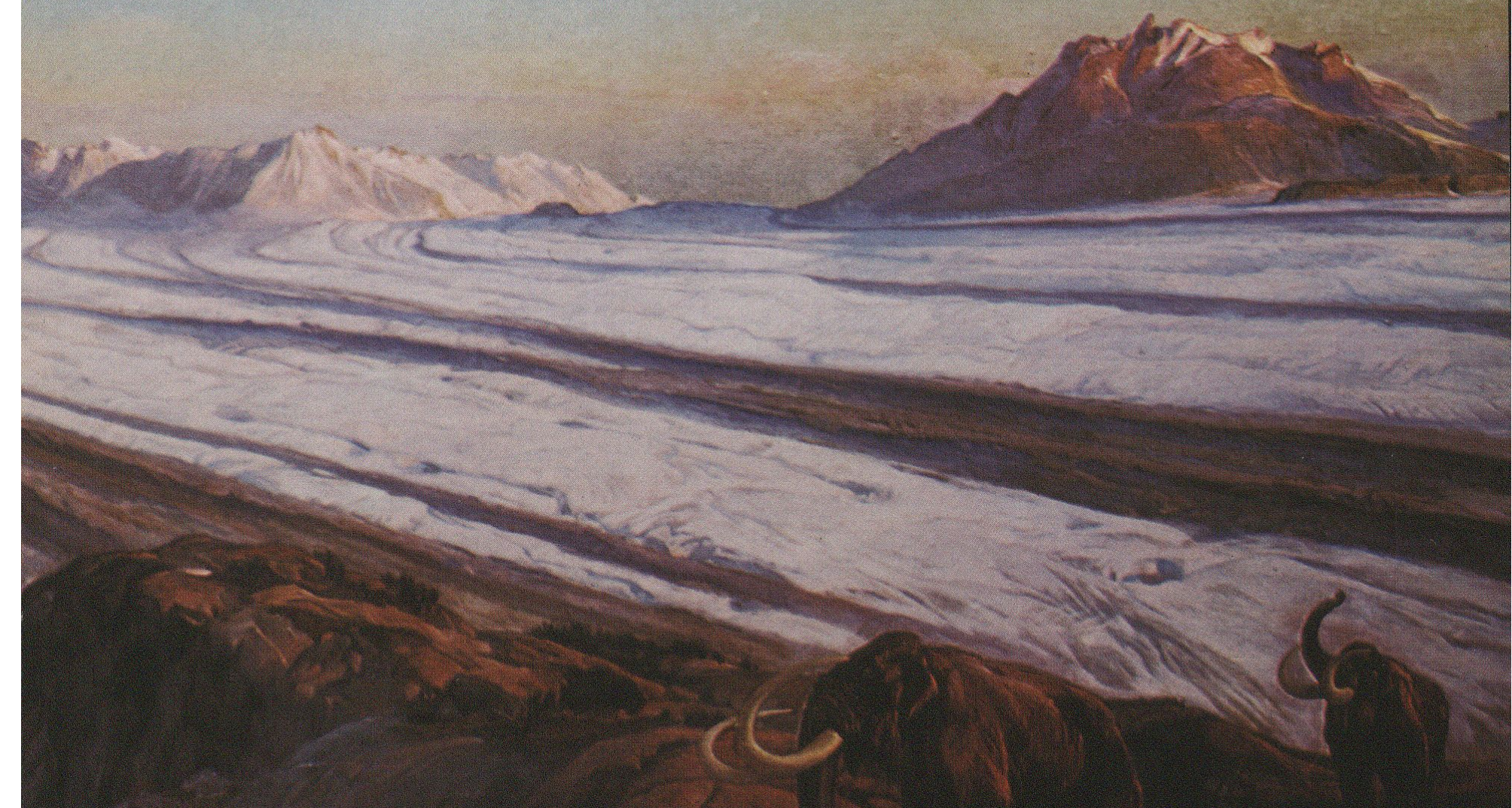




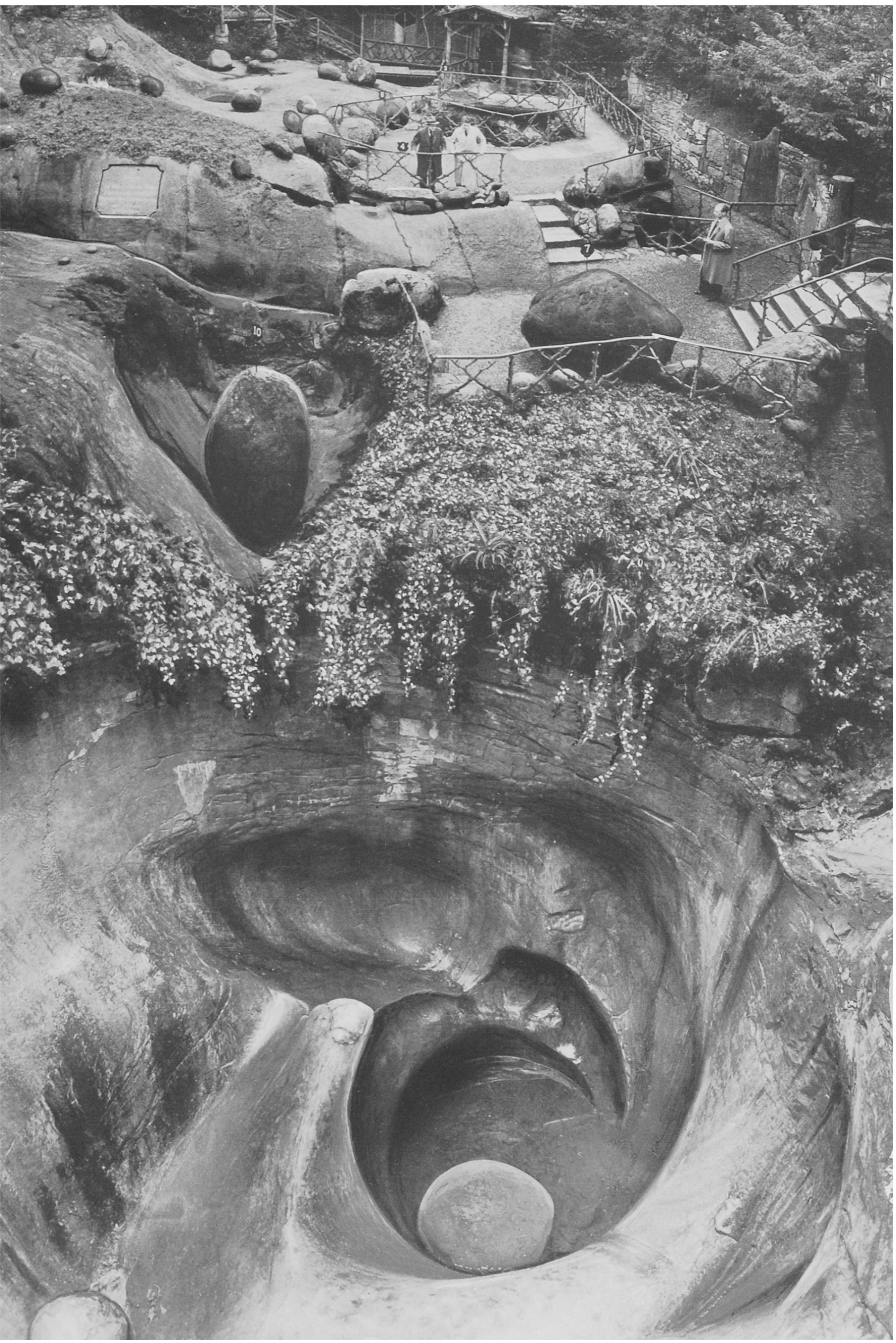


Broschüre erklärt. Der Ingenieur L. Akesson-Amrein, der einige Jahre in der Betriebsleitung mitarbeitete, hatte die Idee, eine „künstliche Gletschermühle in Tätigkeit" einzurichten. In Zusammenarbeit mit Heim und Imfeld entstand 1895/96 im kleinen Tobel des Wesemlinbaches diese Anlage. Im Genre der Zeit blickt man vom Innern einer SAC-Hütte von „anno ehedem” auf ein Gletscherdiorama. Auf der Gletscheroberfläche sind die Schmelzwasserrinnen dargestellt, die plötzlich in einem Spaltensystem verschwinden. Etwas unterhalb dieser „Klubhütte” stürzt in einer künstlich nachgebildeten Eisgrotte ein Wasserfall senkrecht auf einen Gletschertopf hinunter, in dem ein hohler Stein dabei in drehende Bewegung versetzt wird. Die künstliche Gletschermühle blieb bis heute eine vielbestaunte Attraktion, obwohl sie kaum richtig die Entstehung der Gletschertöpfe erklärt. Immerhin war schon der Versuch, in einem Museum eine wissenschaftliche Theorie durch ein bewegliches Modell zu veranschaulichen, der damaligen Zeit weit voraus.

Auf die Initiative eines andern Schwiegersohnes, S. Fischer-Amrein, erhielt der Gletschergarten 1899 eine weitere Attraktion, das Spiegellabyrinth. Diese im sogenannten „maurischen Stil” gestaltete Jahrmarktattraktion wurde für die zweite Schweizerische Landesausstellung 1896 in Genf erstellt. Das umstrittene und durch keine "wissenschaftlichen" Gedankengänge motivierte „Palais des glaces” gehört heute einfach zum Gletschergarten, und - mit seinen 77 Jahren ist der Spiegelsaal nun auch bald museumswürdig. Zum Trost und zur Freude vieler kleiner und grosser Besucher des Gletschergartens sei hier betont, dass auch heute niemand daran denkt, diesen „Spiegelsaal” zu entfernen.

\section{Dr.h.c. Wilhelm Amrein-Küpfer 1872-1946}

Der kurz vor der Entdeckung der Gletschertöpfe geborene einzige Sohn der Familie, Wilhelm Amrein, hielt es als Jugendlicher weder am Gymnasium noch in einer Banklehre lange aus. Dem Existenzzwang folgend, trat er 1894 als Gehilfe beim Hauptzollamt Basel ein. Während der Freizeit besuchte er Kurse des Kaufmännischen Vereins und an der Universität. Nach achtjähriger Beamtenlaufbahn und Auslandaufenthalten, während denen er fremde Sprachen und durch häufigen Besuch von Museen andere Kulturen kennenlernen wollte, kehrte er 1904 wieder nach Luzern zurück. Er arbeitete von da an nebenamtlich im Gletschergarten, leitete für kurze Zeit ein Import-Export-Geschäft und ver- suchte es auch mit einer Champignonkultur im alten Gütschtunnel. Seit 1912 amtete Wilhelm als vollamtlicher Konservator am Gletschergarten. Sein Ziel war, das Museum dem Garten thematisch anzupassen und systematisch zu ordnen. Der Ausbruch des Ersten Weltkrieges setzte aber allen seinen Hoffnungen und Ausbauplänen ein vorläufiges Ende. Die Besucher blieben fern, die Frequenzen sanken wieder auf unter 20000 pro Jahr, und der Gletschergarten musste sich auf die absolut notwendigen Unterhaltsarbeiten beschränken.

1919 trat Marie Amrein-Troller von der Leitung des Gletschergartens zurück. Von nun an arbeiteten Wilhelm als Konservator und Mathilde BlattnerAmrein als Geschäftsführerin in der Betriebsleitung zusammen. In erster Linie gestaltete er etappenweise eine naturkundliche und urgeschichtliche Schau im Sinne eines „alpinen” oder „eiszeitlichen” Museums aus. Das "Heimatmuseum” als Hort heimatlichen Kulturgutes wurde weiter gepflegt. Ein Hauptanliegen W. Amreins war das „Unterrichtsmuseum" im Dienste des Natur- und Heimatschutzes. Er begnügte sich aber nicht allein damit, die genannten Themen einfach im Museum darzustellen. Auf allen Gebieten versuchte er aktiv mitzuwirken und seine Gedanken in eine breite Öffentlichkeit zu tragen. Wilhelm Amrein wurde zu derjenigen Persönlichkeit aus dem Gletschergarten, die wohl die grösste Ausstrahlung nach aussen hin erreichte. Inspiriert durch die Untersuchungen des Alpinen Paläolithikums in den Höhlen Wildkirchli, Wildenmannlisloch und Drachenloch, begann er bereits 1913 mit den ersten Sondierungen in der Höhle Steigelfadbalm an der Rigi. Nach dem Krieg nahm er die Grabungen systematisch auf und fand zu seiner grossen Freude neben Schädel- und andern Knochen des Höhlenbären auch bearbeitete Steine, die hier eine frühe Anwesenheit des Menschen während der Eiszeit vermuten liessen. 1927 entdeckte Amrein die jungsteinzeitliche Höhensiedlung im Langacherwald bei Horw LU. In seiner Arbeit „Urgeschichte des Vierwaldstättersees und der Innerschweiz" veröffentlichte er 1939 seine Forschungsergebnisse. Auf seine Initiative hin begannen 1932 die umfangreichen Ausgrabungen im Wauwilermoos LU.

Als Vorstandsmitglied der Naturforschenden Gesellschaft Luzern präsidierte er die Prähistorische Kommission und die Naturschutzkommission. 1925-1927 war er Präsident der Schweizerischen Gesellschaft für Urgeschichte.

Weitsichtig sah Wilhelm Amrein schon früh die Gefahren falsch verstandenen Fortschritts in Technik und Fremdenverkehr voraus. Er war ein uner-

Gletschertöpfe, Gletscherschliffe und Findlinge im Gletschergarten Luzern. Im Vordergrund der grösste Gletschertopf mit über $9 \mathrm{~m}$ Tiefe und $8 \mathrm{~m}$ Durchmesser 
schrockener Kämpfer für die Ideale des Heimatschutzes, die er in Wort und Schrift verfocht. Wenn man bedenkt, dass ,sein” Gletschergarten teilweise vom Fremdenverkehr lebte, brauchte es Mut, sich ausgerechnet die Exponenten dieser „Industrie” zu Gegnern zu machen. Amrein wusste aber, dass er durch seine Bestrebungen für die Erhaltung der Naturschönheiten auf weite Sicht seiner Vaterstadt mehr dienen konnte, als wenn er geschwiegen hätte.

In den dreissiger Jahren erlebte er die Freude, dass Willy (1914-1935), sein einziger Sohn und vorgesehener Nachfolger im Gletschergarten, dieselben Ziele schon als Gymnasiast in der Presse selbständig verfocht. An der Universität Bern bereitete er sich nach der Matura auf seine zukünftige Aufgabe vor. Ein Badeunfall in der Aare setzte dem hoffnungsvollen Leben ein jähes Ende. Den frühen Tod seines 21 jährigen Sohnes hat W. Amrein-Küpfer nie ganz überwunden.

Die wissenschaftlichen und gemeinnützigen Leistungen W. Amreins wurden in Fachkreisen hoch eingeschätzt: Am Dies academicus der Universität Basel vom 18. November 1938 wurde Wilhelm Amrein für sein gesamtes Lebenswerk im Dienste der urgeschichtlichen Forschung, des Natur- und Heimatschutzes und für seine Tätigkeit im Museum mit der Verleihung der Ehrendoktorwürde ausgezeichnet.

Von den vielgestaltigen Neuerungen und Verbesserungen, die Dr.h. c. Amrein im Gletschergarten durchgeführt hat, blieb bis heute das nach seiner Idee gestaltete Grossgemälde „Luzern zur Eiszeit” ein Höhepunkt. Nach seinem Entwurf auf einer Panoramapostkarte von Luzern verfasste Prof. Albert Heim eine wissenschaftlich ergänzte Vorlageskizze, die der Luzerner Landschaftsmaler Ernst Hodel zur Schaffung des $5 \times 2 \mathrm{~m}$ messenden Eiszeitbildes (1927) auswerten konnte.

\section{Die Stiftung Amrein-Troller, Gletschergarten Luzern}

So wie Dr. h. c. W. Amrein ideell durch das Museum der Öffentlichkeit dienen wollte, entsprach es seiner ganzen Auffassung von der Aufgabe des Gletschergartens, dass er durch die Errichtung einer Stiftung auch materiell einen Beitrag an Forschung, Natur- und Heimatschutz leisten wollte. Er betrachtete die Erben und sich selbst nicht als Besitzer, sondern als Treuhänder des Naturdenkmals. Zudem wusste er aus eigener Erfahrung, wie schwer es war, für urgeschichtliche und geologische Forschungen und für Natur- und Heimatschutzaufgaben Mittel zu finden. Wie mancher Plan musste aus finanziellen Gründen scheitern. Es gab damals weder Nationalfonds noch grossangelegte Aktionen zur Rettung von Kultur- und Naturgütern. Grund zum Ge- danken an eine Stiftung war vor allem auch die Sorge um die Zukunft des Gletschergartens und seine richtige Betreuung, die er am besten gewährleistet sah, indem er ihn aus dem Familienbesitz löste und in die Hände einer öffentlich-rechtlichen Stiftung legte.

Es war wiederum der unermüdliche Freund des Gletschergartens, Albert Heim, der Wilhelm Amrein nach Bern begleitete, als er Prof. Dr. Eugen Huber besuchte. Huber, der Schöpfer des Schweizerischen Zivilgesetzbuches von 1912, bot Gewähr für eine fachmännische Beratung bei der Gründung der Stiftung. Wilhelm Amrein wusste seine Mutter und Schwestern für diesen Weg zu gewinnen. 1920 wurde die Stiftungsurkunde, die 1930 in Kraft trat, von allen Familienmitgliedern unterzeichnet.

Das Stiftungsstatut: Die wesentlichsten Punkte des vierzehn Artikel umfassenden Statutes seien hier zusammengefasst:

Name und Zweck:

„Die Stiftung Amrein-Troller Gletschergarten in Luzern verfolgt den Zweck, den ihr von der Aktiengesellschaft Amrein-Troller schenkungsweise zu Eigentum übertragenen Gletschergarten in Luzern als Naturdenkmal und das anschliessende im Jahr 1895 gegründete populärwissenschaftliche Museum mit den dazu gehörenden Anlagen, Sammlungen, für alle Zukunft zu erhalten, im bisherigen Sinn und Geist weiter zu betreiben, zu entwickeln, den Reinertrag aus dem Betriebe, soweit er nicht für die Stifter und deren Erben bestimmt ist, den Bestrebungen der Schweizerischen Naturforschung und des Heimatschutzes zuzuführen." (Art. 1)

Der Reingewinn der Stiftung wird nach einem 1920 bestimmten Schlüssel verteilt. Zur Zeit stehen je $50 \%$ für die Stifterfamilien und für die Stiftungszwecke zur Verfügung. Ab 1991 lauten die Anteile $25 \%$ an Stifterfamilien und $75 \%$ für Stiftungsgelder. Auf der Liste der zu unterstützenden Werke stehen die Förderung des Natur- und Heimatschutzgedankens in den Schulen, die Urgeschichtsforschung, der Naturschutz (Naturdenkmäler, Reservate), Heimatschutz (landschaftliche Naturschönheiten, charakteristische Bauten etc.), die Erhaltung und Verschönerung des Stadtbildes von Luzern, Publikationen und Veranstaltungen, die zur Förderung der erwähnten Stiftungsziele beitragen, sowie geologische Untersuchungen.

Die Vorschriften zur Verwendung der Gewinne sind flexibel genug gehalten, um den wechselnden Bedürfnissen immer Rechnung zu tragen. Mit Befriedigung kann heute festgestellt werden, dass der grösste Teil der Stiftungsbeiträge sehr nutzbringend eingesetzt werden konnte. Wenn heute verschiedene Forschungsprogramme, die in der Anfangsphase auf die im Vergleich zu heute bescheidenen Beiträge von einigen hundert bis einigen tausend Franken der Stiftung angewiesen waren, nun in vermehr- 
tem Masse vom Nationalfonds unterstützt werden, bedeutet das für die Stiftung zugleich ein Kompliment und eine Entlastung. Mit den freigewordenen Mitteln konnte man wieder an andern Orten, die nicht von der öffentlichen Hand unterstützt werden, einspringen.

Einige Beispiele sollen die Arbeit der Stiftung, die von einem fünfköpfigen Stiftungsrat beaufsichtigt wird, beleuchten.

Regelmässig wurden bis heute von der Stiftung unterstützt: die Prähistorische und die Floristische Kommission der Naturforschenden Gesellschaft Luzern, Exkursionen der Stadt- und Kantonsschulen Luzern, der Innerschweizer Heimatschutz, der Luzerner Naturschutzbund, die Vogelwarte Sempach und die Schweizerische Gesellschaft für Urgeschichte. Auf Beiträge der Stiftung konnte man auch bei verschiedenen Ausgrabungen (z. B. Wauwilermoos LU), bei der Erforschung der Fossilinhalte des Monte San Giorgio durch das Paläontologische Institut Zürich sowie bei verschiedenen Publikationen, Dissertationen und Kartendrucken zählen.

Viele der unterstützten Forscher und Institutionen leisten wertvolle und oft langwierige Grundlagenforschung, die nur in wenigen Fällen zu aufsehenerregenden Resultaten führen. Das ist sicher auch ein Grund, dass diese wichtige kulturelle Aufgabe des Gletschergartens in der Öffentlichkeit sehr wenig bekannt ist.

\section{Der Gletschergarten seit der Gründung der Stiftung}

Dr. h. c. Wilhelm Amrein nutzte die zehn Jahre zwischen der Gründung und dem Inkrafttreten der Stiftung. Er wollte der Stiftung einen Betrieb übergeben, der sowohl in betrieblicher wie auch baulicher Hinsicht den Anforderungen der Zeit genügte. Mit viel Energie versuchte er, einen Teil seiner Pläne durchzuführen und bereicherte das Museum und die Gartenanlagen mit vielen Neuerungen. Das war gut so, denn kaum war die Stiftung in Kraft getreten, begann nach den sogenannten ,goldenen Zwanziger Jahren" die Weltwirtschaftskrise, welcher dann der Zweite Weltkrieg folgte. Wie schon im Ersten Weltkrieg hiess die Devise wieder „Durchhalten”. Dank den vorher getätigten Investitionen und dank den im Gletschergarten ausharrenden Familienangehörigen und dem Personal, die unter minimalsten Lohnbedingungen arbeiten mussten, überstand der Gletschergarten praktisch unbeschadet die mageren Krisen-, Kriegs- und Nachkriegsjahre. Nach dem Tod von Marie Amrein-Troller, der Witwe des Gründers, trat im Jahre 1932 als erster Vertreter der Schweizerischen Naturforschenden Gesellschaft deren Präsident Prof. Dr. E. Rübel in den Stiftungsrat ein. Frau Blattner-Amrein, die seit 1891 in der Geschäftsleitung des Gletschergartens mitarbeitete, übernahm nach dem Tod von Dr. h. c. Amrein-Küpfer im Jahre 1946 die Verwaltung des Gletschergartens. Als sie 1953 zurücktrat, wurde ihr Schwiegersohn Dr. F. J. Roesli (geb. 1899) als Direktor an den Gletschergarten gewählt. Mit ihm stand zum ersten Mal ein Geologe an der Spitze des Betriebes. Dr. F. Roesli arbeitete vorher lange Zeit als Erdölgeologe in New Mexiko, Texas und Griechenland. Für kurze Zeit wirkte er im Auftrage der Unesco bei der Errichtung eines seismologischen Institutes an der Universität von Istanbul mit.

In den fünfziger und sechziger Jahren drängten sich sehr umfangreiche Felssicherungsmassnahmen an den zum Teil gefährlich überhängenden Felspartien an der Nord- und Ostgrenze des Gletschergartens auf. 1960 konnte die Besuchergalerie über dem grossen Relief der Urschweiz eingeweiht werden, die einen Überblick über dieses grossartige Werk Pfyffers erlaubt. Auf der Galerie gestattet seither eine chronologisch geordnete Kartensammlung, das Relief in die Entwicklungsgeschichte der Schweizerischen Kartographie einzustufen.

Ein Hauptanliegen des Geologen F. Roesli ist, den Besuchern wissenschaftlich fundiert und zugleich verständlich darzulegen, was aus dem toten $\mathrm{Ge}$ stein, dem „Buch der Erdgeschichte” herausgelesen werden kann. In ungezählten Führungen und in Form einer im besten Sinne populärwissenschaftlichen Publikation (F. Roesli, 1957) gelang ihm das vorzüglich. Im Bewusstsein, dass hiermit aber nur ein sehr kleiner Teil der Gletschergartenbesucher erfasst werden kann, plante er die bauliche und ausstellungstechnische Veranschaulichung seiner methodischen Ideen. „Wo Steine reden” heisst das Motto des im Jahre 1970 eingeweihten Neubaues. Hier fand das 1927 unter W. Amrein entstandene bekannte Eiszeitbild endlich seinen richtigen Platz. Das entsprechende Wandbild „Luzern zur Miozänzeit" gestaltete der Luzerner Surrealist Ernst Maass. Nach wissenschaftlicher Beratung von Prof. E. Kuhn-Schnyder, Prof. R. Hantke und Dr. F. Roesli gelang dem begabten Künstler eine eindrückliche Rekonstruktion der subtropischen tertiären Küstenlandschaft.

Nach der Demission von Dr. F. Roesli trat 1969 mit C. Clément (lic. phil. I, Urgeschichte) erstmals seit Bestehen des Gletschergartens ein Leiter in den Betrieb ein, der nicht der Familie angehörte. Seit 1971 betreut P. Wick (dipl. phil. II, Geograph) den Gletschergarten Luzern.

\section{Ausblick}

Einige Probleme des Gletschergartens wurden schon in den vorangehenden Kapiteln berührt. Die zunehmende Verwitterung des Sandsteinfelsens, 
welche das Naturdenkmal Gletschergarten heute bedroht, stellt ein sehr dringendes Problem dar. Mehr als zehntausend Jahre lang lagen die Gletscherschliffe und Gletschertöpfe gut geschützt unter einer Moränendecke. Seit der Abdeckung vor hundert Jahren lösen die im Sicker- und Niederschlagswasser enthaltenen Säuren das Kalkbindemittel, das die einzelnen Sandkörner zusammenkittete. Auf der schwammig gewordenen Felsoberfläche setzen sich sofort Moose, Algen und Flechten fest, die ihrerseits den Feuchtigkeits- und Säuregehalt wieder heben. Im dicht mit Schichtfugen und Klüften durchsetzten Fels hat die Frostsprengung ein gutes Angriffsfeld. Bis heute wird die Felsoberfläche alljährlich mittels harten Bürsten vom Pflanzenbesatz gereinigt, was aber für die feinen Gletscherschrammen eine „Rosskur” bedeutet. Im Winter wird jeweils die gesamte Felspartie zugedeckt. Diese Methode schützt den Felsen sehr gut. Die Nachteile liegen aber auf der Hand: Der Gletschergarten kann im Winter nicht besichtigt werden, und während der übrigen neun Monate ist der Fels ungeschützt. Besonders in den langen Nebelperioden im Herbst, wenn die Ölfeuerungen der ganzen Stadt in Betrieb sind, wenn auf der benachbarten Hauptverkehrsstrasse kein Luftzug die Abgase wegbläst, und wenn der an faule Eier erinnernde penetrante Geruch einer nahen chemischen Industrie sich über die Stadt ausbreitet, dann ahnt man, welch aggressiver Segen auf das Naturdenkmal hinunterrieselt. Obwohl es nach Ansicht von Fachleuten bis heute noch keine absolut befriedigende und genügend getestete Konservierungsmethode für Sandsteindenkmäler gibt, wird der Gletschergarten in nächster Zeit versuchen müssen, dieses Problem so gut wie möglich zu lösen. Die beim Löwendenkmal ebenfalls in anstehendem Fels angewandte Methode, die Verwitterungsschicht einfach zu entfernen, fällt bei einem Naturdenkmal, wo die natürliche Oberfläche erhalten werden muss, ausser Betracht.

Das Museumsgebäude und seine Anbauten stammen zu einem grossen Teil noch aus den Gründerund Ausbaujahren zwischen 1874 und 1914. Über $71 \frac{1}{2}$ Millionen Besucher haben inzwischen dieses Haus betreten.

Das Museum bietet eine sehr grosse, vielleicht fast zu grosse Vielfalt an Ausstellungsobjekten. Der Leser dieser Geschichte des Gletschergartens und seiner Familie mag dieser Vielfalt Verständnis entge- genbringen. Jedes Ausstellungsobjekt und jeder Museumsraum zeugt von den verschiedenartigen Interessen und Tätigkeitsgebieten der einzelnen Familienmitglieder, die im Gletschergarten gewirkt haben. Dieses Verständnis darf aber von allen andern Besuchern weder erwartet noch bei diesen vorausgesetzt werden. Eine Neukonzeption des Museumsgebäudes und ein übersichtlicheres Ordnen der Ausstellungsthemen wird deshalb eine weitere zukünftige Aufgabe der Stiftung sein. Die vorgesehenen Themen sind durch das Naturdenkmal und durch die bereits vorhandenen wichtigeren Ausstellungsgüter gegeben. Schon ist durch die Verwirklichung des Neuanbaues die unmittelbare Verbindung zum Naturdenkmal hergestellt. Ein weiterer Ausbau des Themakreises „Eiszeit” drängt sich auf. Dabei sollen sowohl geologische und geomorphologische wie auch botanische, zoologische und anthropologische Besonderheiten dieses Zeitalters veranschaulicht werden. Daneben werden auch in Zukunft ältere erdgeschichtlich interessante Objekte zur Ausstellung gelangen. Ein besonderer Stolz des Museums, die Reliefsammlung, die in wenigen, aber qualitativ hochstehenden Einzelstücken vom ältesten Relief der Schweiz bis zum Höhepunkt der Reliefkunst führt, kann zum Teil in den geologischen Teil integriert werden.

Die Aufgaben der nächsten Zukunft - die Konservierung des Naturdenkmals, die Sanierung der baulichen Strukturen und die Museumsgestaltung - bedeuten für den Gletschergarten einen sehr hohen zeitlichen und finanziellen Aufwand.

Heute kann die Stiftung Amrein-Troller aber zuversichtlich in die Zukunft blicken. Der Gletschergarten, der dank dem Gründerehepaar Amrein-Troller und deren Nachkommen sich über gute und schlechte Zeiten selbständig aufbauen, erweitern und erhalten konnte, hat guten Grund dafür. Die immer zahlreicher eintreffenden interessierten Besucher, deren Zahl sich bis zum hundertsten Betriebsjahr 1972 auf eine Rekordhöhe von 160000 steigerte, zeigen deutlich genug, dass das Naturdenkmal mit seinem Museum trotz der erwähnten Probleme noch nichts an Lebendigkeit und Attraktivität eingebüsst hat. Die Stiftung Amrein-Troller, Gletschergarten Luzern wird weiterhin mit allen Kräften versuchen, neben ihrem Hauptzweck, das Naturdenkmal und das Museum zu erhalten und weiterzuentwickeln, auch ihrer kulturellen Aufgabe nach aussen hin nachzukommen. 